\title{
APRESENTAÇÃO DOSSIÊ INTERSEÇÕES ENTRE ESTUDOS SOBRE MOVIMENTOS SOCIAIS E ESTUDOS SOCIAIS DE CIÊNCIA E TECNOLOGIA
}

\author{
PRESENTATION DOSSIER INTERSECTIONS BETWEEN \\ STUDIES ON SOCIAL MOVEMENTS AND SOCIAL STUDIES OF \\ SCIENCE AND TECHNOLOGY
}

Thiago Coacci ${ }^{1}$

Priscila Delgado Carvalho

Os estudos sociais da ciência e tecnologia (CTS) são um campo interdisciplinar, fértil e em rápido crescimento no Brasil e no mundo. Há décadas, pesquisadores e pesquisadoras de variadas disciplinas têm buscado refletir sobre as relações da sociedade com a ciência e a tecnologia. Buscando superar explicações que colocam o vetor de causalidade exclusivamente na sociedade ou na tecnologia, esse campo aposta em análises simétricas e que estejam atentas às formas de coprodução. Dentro dessa ampla agenda de pesquisa, e em interseção com vertentes diversas como teorias feministas e do ator-rede, há um esforço - mesmo que ainda inicial - de compreender o papel dos movimentos sociais nessa dinâmica complexa entre política, sociedade, ciência e tecnologia.

De forma pioneira, Steven Epstein (1996) analisou a forma como o movimento LGBT estadunidense enfrentou a crise da AIDS por meio da produção de conhecimento. Ativistas se tornaram experts no conhecimento científico disponível sobre a AIDS, realizaram experimentos científicos em seus próprios corpos, assim, alteraram o conhecimento disponível sobre o tema e influenciaram a resposta do Estado à epidemia. Outro exemplo é o estudo de Sabrina

\footnotetext{
${ }^{1}$ Doutor em Ciência Política - UFMG. Pesquisador vinculado ao Núcleo de Estudos e Pesquisas da MulherNEPEM/UFMG. e-mail: thiagocoacci@gmail.com

${ }^{2}$ Doutora em Ciência Política - UFMG. e-mail: prisciladcarvalho@gmail.com
} 


\section{Debates Insubmissos}

Revista

McCormick (2009) sobre a história do movimento contra o câncer de mama nos Estados Unidos ou o estudo de Coacci (2020) sobre como o movimento de pessoas trans no Brasil tem produzido relatórios de assassinatos para dialogar com o Estado e organizações internacionais.

Esse campo também tem observado as recentes transições políticas do mundo, os processos de desdemocratização e ascensão da nova direita, buscando identificar como tais e processos são influenciados por uma conexão entre movimentos sociais não emancipatórios, ciência e tecnologia. Exemplo dessa corrente é o trabalho de Tom Waidzunas (2015) que analisa a maneira como a pseudo-ciência das terapias de cura gay alterou o campo científico da psiquiatria e da psicologia sobre a sexualidade e tem influenciado o discurso político conservador nos Estados Unidos e outros países como Uganda.

Há ainda autores de origens disciplinares diversas que vêm se utilizando das categorias teóricas e metodológicas dos estudos de ciência e tecnologia para analisar a conformação de movimentos sociais, a permanência das organizações que eles estabelecem e suas interações com o Estado e sociedade. Trabalhos nesse sentido passam pela compreensão das assemblages ou agenciamentos - termos que vêm sendo usados em pesquisas sobre movimentos globais pós2011 e suas intrincadas redes de poder - como em Conway, Osthereweil e Thorbur (2018). Entendendo a ação como um efeito relacional, em diálogo com a teoria do ator-rede, Featherstone (2008) estuda conexões entre espaço, identidades políticas e resistência nos ativismos de grupos subalternos em meio à globalização. Nessa perspectiva, a agência desses grupos é baseada na construção de "geografias de poder de modos antagonísticos" (2008, p.10) Outras pesquisas enfocam como objetos - incorporados como actantes nas redes de ativismo analisadas a partir de abordagem simétrica - tornam-se elementos centrais para sua existência e seu funcionamento. É o que faz Rodríguez-Giralt (2011) em estudo sobre a tragédia ambiental de Doñana, na Espanha, na qual os pássaros emergiram não apenas como recurso usado pelo movimento ambientalista, mas como mediadores, sempre e quando permitiram a coordenação de práticas. Conflitos ambientais também marcam o trabalho de Lorena Fleury (2013) sobre a construção da Usina Hidrelétrica de Belo Monte, articulando as redes sociotécnicas à política ontológica de Stengers (2007) e de La Cadena (2010). 


\section{Revista \\ Debates Insubmissos}

No Brasil, outros estudos vêm valendo-se da teoria do ator-rede para analisar como coletivos se formam e transformam nas disputas e controvérsias em que se engajam, a exemplo do trabalho de Camila Penna (2014) sobre as controvérsias que perpassam as políticas de reforma agrária no Incra. Marcelo Rosa dialoga com Law (2004) e relê as articulações internacionais do MST a partir dos "modos de compilar", ou dos processos, sempre instáveis e circunstanciais, de reunir elementos que permitem o estabelecimento de disputas. Dialogando com essa categoria, Priscila Carvalho (2020) estuda como as conexões estabelecidas por movimentos rurais em suas práticas acabam transformando a própria existência desses coletivos. Alguns desses trabalhos apontam, inclusive, para possibilidades de interseção entre essas teorias e as abordagens teóricas decoloniais, sugerindo tratar-se de metodologias úteis para permitir a emergência de agências e ontologias que costumam passar à margem daquelas percebidas nas narrativas estruturadas sob lentes das teorias sociais hegemônicas (Rosa, 2016). Há, portanto, como aponta esse autor, convergências teóricas e políticas possíveis entre essas agendas de pesquisa.

Nesse sentido, o presente dossiê buscou aprofundar o diálogo entre as tradições de estudos de movimentos sociais e os estudos sociais de ciência e tecnologia no Brasil, sendo composto por três trabalhos que oferecem diferentes miradas a esse diálogo, tanto do ponto de vista teórico quanto dos objetos de análise.

O trabalho que abre o dossiê é o de Joaquim Pinho Pinheiro (UnB), Controvérsias e produção do conhecimento sobre movimentos sociais do campo no Brasil. O autor contribui com a literatura ao direcionar sua análise para a produção científica nas ciências sociais. Analisa três controvérsias disparadas a partir da obra do sociólogo José de Souza Martins em meados da década de 1990. O artigo buscou demonstrar a influência de fatores extracientíficos no discurso científico, assim, a medida que Martins se afastou dos movimentos sociais do campo e se aproximou do governo FHC, sua produção sociológica também se alterou, passando a tecer críticas mais pesadas ao MST e também a jovens sociólogos que, em sua perspectiva, fariam "sociologia militante". Como Pinheiro argumenta, a ironia nessa crítica está no fato de que se, por um lado, Martins percebia a influência da ideologia dos movimentos sociais no trabalho 


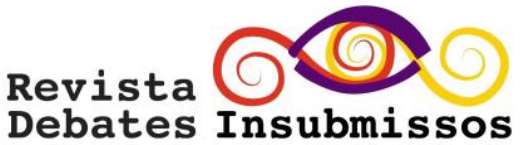

dessa nova geração de sociólogos, não percebia - ou ao menos se omitia sobre - como o seu próprio trabalho também estava sendo intensamente influenciado pela ideologia política do governo com que colaborava.

Os outros dois trabalhos bebem de uma tradição específica dos estudos sociais de ciência e tecnologia, a teoria do ator-rede, para analisar distintos aspectos dos movimentos sociais. O primeiro desses textos é o Agencia desde el ensamblaje: el caso de tres movimientos ambientales en colombia, de Diana Yizel Goyes Valencia (Corporación Universitaria Minuto de Dios/Colômbia) e Vanessa Ortiz Piedrahita (Universidad Nacional de Colombia). O trabalho analisa os casos do Comité Ambiental en Defensa de la Vida (CADV), Colectivo Sembrando Ando (MSA) e Agenda Ambiental (AAM) comparando seus repertórios de ação e processos de agenciamento. Ao fazer isso, identifica como a ação desses movimentos é influenciada por fatores estruturais, mas também por aspectos relacionais e por atores não humanos que, em conjunto, possibilitam a agência.

O terceiro trabalho move o foco dos repertórios e da agência para as relações entre movimentos e Estado, principalmente para as instituições participativas ou interfaces socioestatais. Em Open Government Partnership: laboratório teórico com a antropologia da tecnologia e a teoria ator-rede Matheus Henrique Souza Santos (Unicamp) e Milena Pavan Serafim (Unicamp) argumentam que a OGP não pode ser interpretada apenas como um conjunto de princípios que devem ser adotados por governos para facilitar acesso a dados, ampliar a transparência e o diálogo entre Estado e sociedade civil, mas a OGP em si seria um ator não humano, nos termos de Bruno Latour.

Esperamos que as discussões aqui contidas sejam apenas um convite para aprofundarmos cada vez mais o diálogo entre os movimentos sociais, a ciência e a tecnologia. Boa leitura! 


\section{REFERÊNCIAS}

CARVALHO, Priscila. D. Além da Forma-Movimento: Compilações do Movimento dos Pequenos Agricultores. Revista Brasileira De Sociologia, v. 8, p. 83-106, 2020.

COACCI, Thiago. Contando as mortes: coproduzindo gênero, conhecimento e política no movimento trans. in: FACCHINI, Regina; LINS FRANÇA, Isadora. (Org.) Direitos em disputa: LGBTI+, poder e diferença no Brasil contemporâneo. Campinas: Editora Unicamp, 2020

CONWAY, Janet. M.; OSTERWEIL, Michal.; THORBURN, Elise. Theorizing Power, Difference and the Politics of Social Change: Problems and Possibilities in Assemblage Thinking. Studies in Social Justice, v. 12, n. 1, p. 1-18, 12 jul. 2018.

DE LA CADENA, Marisol. Indigenous Cosmopolitics in the Andes: Conceptual Reflections beyond Politics. Cultural Anthropology. 25, 2010, p. 334 - 370. 10.1111/j.15481360.2010.01061.x.

EPSTEIN, Steven. Impure science: AIDS, activism, and the politics of knowledge. Berkeley:

University of California Press, 1996

FEATHERSTONE, David, Resistance, Space and Political Identities: The Making of Counter-Global Networks. West Sussex: Wiley-Blackwell, 2008. ISBN: 9781405158084,9781444305050

FLEURY, Lorena Cândido and ALMEIDA, Jalcione. A construção da Usina Hidrelétrica de Belo Monte: conflito ambiental e o dilema do desenvolvimento. Ambient. soc. [online]. 2013, vol.16, n.4, pp.141-156. ISSN 1809-4422.

LAW, John. After Method. Mess in social science research. New York: Routledge, 2004.

PENNA, Camila. Conexões e controvérsias no Incra de Marabá. O Estado como um ator heterogêneo. Rio de Janeiro: Garamond, 2015.

ROSA, Marcelo, "A journey with the Movimento dos Trabalhadores Rurais sem Terra (MST) across Brazil and on to South Africa". Études Rurales, v. 196, 2015, p. 43-56.

MCCORMICK, Sabrina. Mobilizing science: movements, participation, and the remaking of knowledge. Philadelphia: Temple University Press, 2009.

RODRÍGUEZ-GIRALT, Israel. Social movements as actor-networks: Prospects for a symmetrical approach to Doñana's environmentalist protests. Convergencia, v. 18, n. 56, p. 13-35, 2011. 
ROSA, Marcelo. C. Sociologies of the South and the actor-network-theory: Possible convergences for an ontoformative sociology. European Journal of Social Theory, v. 19, n. 4, p. 485-502, nov. 2016.

STENGERS, Isabelle. La proposition cosmopolitique. In: LOLIVE, J. SOUBEYRAN, O. L'emergence des cosmopolitiques. Paris: La Découverte. 2007.

WAIDZUNAS, Tom. The Straight Line. How the Fringe Science of Ex-Gay Therapy Reoriented Sexuality. Minneapolis: University of Minnesota Press, 2015. 